\title{
HUBUNGAN PENGETAHUAN, MOTIVASI, DAN SIKAP DENGAN KEPATUHAN DIET PADA PENDERITA DM TIPE 2 DI WILAYAH KERJA PUSKESMAS SUDIANG RAYA KOTA MAKASSAR.
}

\author{
The Correlation Knowledge, Motivation, and Attitude With Diet Compliance in Patients with Diabetes Mellitus Type 2 \\ At Sudiang Raya Public Health Center Makassar. \\ Rahmiyanti, Hj.Ningsih Jaya ${ }^{2}, \mathrm{Hj}$. Muhasidah $^{3}$ \\ Program studi D-IV Keperawatan \\ Poltekkes Kemenkes Makassar \\ *) rahmiyanti307@gmail.com
}

\begin{abstract}
In stabilizing blood glucose levels in patients with DM especially DM type 2, through increasing diet compliance, diet compliance is very important to achieve success in treatment. Obedience is an individual's willingness to do something that is expected or requested by the authority or power holder which is marked by willingness, obedience, and making a desire to meet the expectations or adjusted expectations of others. The purpose of this study was to determine the correlation of knowledge, motivation, and attitude with diet compliance in patients with type 2 diabetes. The method was to cross-sectional research. The sampling technique in this study was the non-random sampling technique with a purposive sampling method with a total sample of 51 people. The results of this study indicated based on chi-square analysis found there was a correlation between knowledge with diet compliance with a significant value $(p=0,000)$, there was a correlation between motivation with diet compliance with a significant value $(p=0.003)$, there was a correlation between attitude and diet compliance with a significant value $(p=0.001)$. So it can be concluded that there was a correlation between knowledge, motivation, and attitude with diet compliance in patients with Type 2 diabetes.
\end{abstract}

Keywords: DM Type 2, Knowledge, Motivation, Attitude, Diet Compliance.

\section{ABSTRAK}

Dalam menstabilkan kadar glukosa darah pada penderita DM terutama DM tipe 2 yaitu meningkatkan kepatuhan dietnya, kepatuhan diet ini sangat berperan penting guna untuk mencapai keberhasilan dalam terapi. Kepatuhan adalah kerelaan individu untuk melakukan sesuatu yang diharapkan atau diminta oleh pemegang otoritas atau kekuasaan yang ditandai dengan kerelaan, mengalah, membuat suatu keinginan konformitas dengan harapan atau kemauan orang lain sehingga dapat menyesuaikan diri. Tujuan dari penelitian ini adalah Untuk mengetahui hubungan pengetahuan, motivasi, dan sikap dengan kepatuhan diet pada penderita DM tipe 2. Metode penelitian cross sectional. Teknik pengambilan sampel dalam penelitian ini teknik non random sampling dengan metode purposive sampling dengan jumlah sampel sebanyak 51 orang. Hasil penelitian ini menunjukkan berdasarkan analisis chi - square didapatkan ada hubungan pengetahuan dengan kepatuhan diet dengan nilai bermakna $(p=0,000)$, ada hubungan motivasi dengan kepatuhan diet dengan nilai bermakna $(\mathrm{p}=0,003)$, ada hubungan sikap dengan kepatuhan diet dengan nilai bermakna $(p=0,001)$.sehingga dapat disimpulkan bahwa ada hubungan prngetahuan, motivasi, dan sikap dengan kepatuhan diet pada penderita DM Tipe 2 .

Kata Kunci : DM Tipe 2, pengetahuan, motivasi, sikap, kepatuhan diet.

\section{PENDAHULUAN}

Diabetes telah menjadi penyakit umum yang bisa kita temukan dimana-mana.angka kejadiannyapun terus melonjak tajam, bahkan cenderung menakutkan jika mengingat komplikasi yang disebabkan pada mata, jantung, ginjal, saraf, atau kemungkinan amputasi juga terjadi.

Berdasarkan hasil data laporan WHO (World Health Organization) tahun 2016 jumlah pasien diabetes mellitus diseluruh dunia per regional di tahun
2015 dan tahun 2040 (umur 20-70 tahun) yakni di tahun 2015 sebanyak 415 juta orang dewasa dengan diabetes dan di tahun 2040 mendatang, diperkirakan jumlah pasien diabetes melitus meningkat menjadi 642 juta orang.

Informasi terbaru berdasarkan data IDF (International Diabetes Federation) Atlas, (2017) menunjukkan bahwa diseluruh dunia pada tahun 2017 terdapat 425 juta orang menderita DM, dan diperkirakan akan meningkat pada tahun 2045 
mendatang menjadi 629 juta orang akan menderita DM, serta pada tahun 2045 mendatang diperkirakan Indonesia masuk 10 besar yaitu berada pada posisi ke6 dengan penderita DM sebanyak 167 juta orang setelah Negara China, India, United States, Brazil, dan Mexico.

Hasil Riskesdas dari tahun 2013-2018 menunjukkan bahwa hasil prevalensi diabetes melitus di Indonesia berada pada usia diatas 15 tahun menurut diagnosis dokter tahun 2018 yaitu 2,0\% lebih tinggi dibanding tahun 2013 yaitu 1,5\%. Berdasarkan hasil Riskesdas tahun 2018 sebanyak 34 Provinsi di Indonesia menunjukkan kenaikan angka kejadian DM .

Kemenkes (2015) telah mencatat prevalensi pada penduduk di atas 15 tahun berdasarkan Kabupaten/Kota di Provinsi Sulawesi Selatan menunjukkan 3,4 \%, dapat dikatakan 3 dari 100 penduduk di Sulawesi selatan di atas usia 15 tahun menderita DM.

Berdasarkan data Kemenkes, (2015) Prevalensi DM di Kota Makassar pada usia di atas 15 tahun berdasarkan diagnosis dokter atau gejala yaitu $5,3 \%$, demikian pula kejadian penyakit DM di kota Makassar menduduki peringkat ke-2 setelah Tanah Toraja yaitu 5,3 \% (Makassar) dan 6,1 \% (Toraja).

Berdasarkan hasil survei P2PL, terdapat kasus baru DM di Kota Makassar tahun 2015 yaitu 21.018, kasus lama yaitu 57.087, dan kematian yaitu 811 orang (Dewi et al., 2018). Sedangkan di Puskesmas Sudiang Raya Kecamatan Biringkanaya Kota Makassar pada bulan Desember 2018 terdapat 50 orang yang berkunjung dengan kasus Diabetes Melitus.

Dari beberapa penelitian sebelumnya, salah satunya penelitian yang dilakukan oleh Okatiranti dan Hardiyanti (2016) dengan judul " Gambaran pengetahuan, sikap dan kepercayaan terhadap diet penderita DM di RSUD Kota Bandung" didapatkan hasil bahwa $(44,06 \%)$ memiliki tingkat pengetahuan yang kurang, lalu yang memiliki pengetahuan cukup yaitu $(42,37 \%)$, dan $(13,55 \%)$ memiliki tingkat pengetahuan yang baik. Untuk sikap (59,32\%) bersikap positif, dan $(40,67 \%)$ bersikap negatif. Untuk kepercayaan $(52,54$ $\%)$ memiliki kepercayaan tinggi, dan yang memiliki kepercayaan kurang yakni $(47,45 \%)$. Penderita Diabetes tipe 2 di RSUD kota Bandung memiliki tingkat pengetahuan yang kurang, sedangkan sikap yang dimiliki positif, dan kepercayaannya tinggi terhadap diet.

Penelitian terkait lainnya yang dilakukan oleh Isnaini dan Saputra (2017) dengan judul "Pengetahuan dan motivasi meningkatkan kepatuhan diet pasien diabetes melitus tipe 2" didapatkan hasil bahwa dari 40 responden sebagian besar pengetahuan responden adalah baik sebanyak 24 responden $(60 \%)$ dan sisanya memiliki pengetahuan kurang sebanyak 16 responden $(40 \%)$. Sebagian besar motivasi responden adalah tinggi sebanyak 22 responden (55\%) dan sebagian kecil memiliki motivasi rendah sebanyak 18 responden (45\%). Sebagian besar responden patuh terhadap diet yaitu sebanyak 21 responden $(52,5 \%)$ dan sebagian kecil memiliki kepatuhan diit yang tidak patuh sebanyak 19 responden $(47,5 \%)$.

Dalam menstabilkan kadar glukosa darah pada penderita DM terutama DM tipe 2 yaitu meningkatkan kepatuhan dietnya, kepatuhan diet ini sangat berperan penting guna untuk mencapai keberhasilan dalam terapi.kepatuhan merupakan hal yang sangat penting Karena dapat mengembangkan kebiasaan yang dapat membantu penderita DM tipe 2 dalam mengikuti jadwal dietnya. Menurut Lopulalan (2008) dalam (Dewi et al., 2018).

Pasien dengan Diabetes Melitus Tipe II sangat membutuhkan motivasi yang tinggi dalam menjalankan terapinya, karena terapi yang dijalani menimbulkan rasa bosan dan jenuh. Pengetahuan yang cukup akan faktor pencetus dan resiko yang akan ditimbulkan dari penyakit DM Tipe II dapat meningkatkan motivasi dalam menjalankan terapi diet (Notoatmodjo, 2007) dalam (Pujiastuti, 2017)

Dari penjelasan di atas yang telah dikemukakan, peneliti tertarik dan mengangkat sebuah judul "Hubungan Pengetahuan, Motivasi, dan Sikap dengan Kepatuhan Diet Pada Penderita Diabetes Melitus" di Wilayah kerja Puskesmas Sudiang Raya kota Makassar.

\section{METODE PENELITIAN}

Penelitian ini menggunakan jenis penelitian kuantitatif dengan menggunakan desain penelitian deskriptif analitik serta menggunakan rancangan penelitian cross sectional untuk melihat hubungan pengetahuan, motivasi dan sikap dengan kepatuhan diet penderita DM tipe 2 di wilayah kerja puskesmas sudiang raya kota Makassar.

Metode cross sectional yaitu penelitian yang mengambil satu kali data variabel dependen dan variabel independen, keduanya dilakukan dalam sekali waktu (simultan) (Donsu, 2017).

Penelitian ini dilakukan pada tanggal 10 mei 2019 - 10 juni 2019 di Wilayah Kerja Puskesmass Sudiang Raya Kota Makassar

Populasi dalam penelitian ini adalah semua pasien penderita DM yang berobat di Puskesmas Sudiang Raya Kota Makassar dengan jumlah populasi penderita DM sebanyak 71 orang di bulan Maret 2019. 
Teknik sampling yang digunakan dalam penelitian ini adalah teknik non random sampling dengan metode purposive sampling, yaitu peneliti menetapkan responden yang menjadi sampel berdasarkan pertimbangannya (Riyanto, 2017). sampel yang diambil sesuai dengan kriteria yang telah ditetapkan, Kriteria Inklusi penelitian ini adalah : Pasien Bersedia menjadi responden, Pasien diabetes mellitus tipe 2, Pasien yang berobat di puskesmas sudiang raya, Pasien dalam keadaan sadar dan kooperatif, Pasien yang dapat berkomunikasi dengan baik. Sedangkan Kriteria eksklusi yaitu : Pasien penelitian dalam keadaan opname, Pasien tidak berada di Wilayah Kerja Puskesmas Sudiang Raya, Pasien mengundurkan diri.

Jumlah sampel yang diperoleh berdasarkan rumus Slovin sebanyak 60 akan tetapi dikarenakan beberapa sampel tidak bersedia sehingga jumlah sampel yang didapatkan hanya 51 orang dengan door to door ke rumah responden dan beberapa responden didapatkan saat berkunjung ke puskesmas Sudiang Raya Kota Makassar.

Sumber data penelitian adalah data primer yakni data yang diperoleh langsung menggunakan instrumen kuesioner dan data diperoleh oleh peneliti dari berbagai sumber data dan instansi terkait yang ada di wilayah kerja puskesmas sudiang raya kota Makassar.

Untuk kuesioner yang digunakan terdiri atas data demografi meliputi nama, usia, jenis kelamin, pendidikan, pekerjaan, lama menderita DM, riwayat DM keluarga. Untuk kuesioner pengetahuan terdiri dari 10 pertanyaan dengan menggunakan skala Gutman, sedangkan untuk kuesioner motivasi, sikap dan kepatuhan diet terdiri dari 10 pertanyaan dengan menggunakan skala Likert.

Setelah dilakukan pengumpulan data, lalu dilakukan analisis data untuk mengetahui apakah ada hubungan pengetahuan, motivasi dan sikap dengan kepatuhan diet pada penderita DM Tipe II di wilayah kerja puskesmas sudiang raya. Dengan menggunakan Uji Chi Square dengan nilai batas kemaknaan alfa 5\% $(0,05)$.
HASIL PENELITIAN

Gambaran Umum Responden

Tabel 4.1

Distribusi Frekuensi Subjek Penelitian Menurut Umur di Wilayah Kerja Puskesmas Sudiang Raya Kota Makassar 2019

\begin{tabular}{lll}
\hline Usia & $\begin{array}{l}\text { Frekuens } \\
\mathrm{i}(\mathrm{f})\end{array}$ & Presentase (\%) \\
\hline $36-45$ & 7 & $13,7 \%$ \\
$46-55$ & 23 & $45,1 \%$ \\
$56-65$ & 15 & $29,4 \%$ \\
$>65$ & 6 & $11,8 \%$ \\
& & \\
\hline Total & 51 & 100,0 \\
\hline
\end{tabular}

Sumber Data Primer

Berdasarkan tabel 4.1 dapat diketahui bahwa penderita Diabetes Melitus Tipe 2 di Wilayah Kerja Puskesmas Sudiang Raya Kota Makassar berusia 3645 tahun sebanyak 7 orang $(13,7 \%)$, yang berusia 46 55 tahun sebanyak 23 orang $(45,1 \%)$, yang berusia 56-65 tahun sebanyak 15 orang $(29,4 \%)$, yang berusia $>65$ tahun sebanyak 6 orang $(11,8 \%)$. Rata-rata usia yang didapatkan pada penderita Diabetes Melitus di Wilayah Kerja Puskesmas Sudiang Raya kota Makassar yaitu 46-55 tahun dengan presentase (45, 1 $\%)$ sebanyak 23 orang.

Tabel 4.2

Distribusi Frekuensi Subjek Penelitian Menurut Jenis Kelamin di Wilayah Kerja Puskesmas Sudiang Raya Kota Makassar 2019

\begin{tabular}{lll}
\hline Jenis Kelamin & $\begin{array}{l}\text { Frekuensi } \\
\text { (f) }\end{array}$ & $\begin{array}{l}\text { Presentase } \\
(\%)\end{array}$ \\
\hline Perempuan & 35 & $68,6 \%$ \\
Laki-laki & 16 & $31,4 \%$ \\
\hline Total & 51 & 100,0
\end{tabular}

\begin{tabular}{lrl}
\hline Total & 51 & 100,0 \\
\hline Sumber : Data Primer
\end{tabular}

Berdasarkan tabel 4.2 dapat diketahui bahwa penderita Diabetes Melitus di Wilayah Kerja Puskesmas Sudiang Raya Kota Makassar sebagian besar berjenis kelamin perempuan sebanyak 35 orang $\quad(68,6 \%)$ dan sebagian kecil berjenis kelamin laki-laki sebanyak 16 orang $(31,4 \%)$. Rata-rata subjek penelitian berjenis kelamin perempuan dengan presentase $68,6 \%$. 


\begin{tabular}{|c|c|c|}
\hline \multicolumn{3}{|c|}{$\begin{array}{c}\text { Tabel 4.3 } \\
\text { Distribusi Frekuensi Subjek Penelitian Menurut } \\
\text { Pendidikan di Wilayah Kerja Puskesmas } \\
\text { Sudiang Raya Kota Makassar } 2019\end{array}$} \\
\hline $\begin{array}{l}\text { Kategori } \\
\text { Pendidikan }\end{array}$ & $\begin{array}{l}\text { Frekuensi } \\
\text { (f) }\end{array}$ & $\begin{array}{l}\text { Presentase } \\
(\%)\end{array}$ \\
\hline SD & 12 & $23,5 \%$ \\
\hline SMP & 14 & $27,5 \%$ \\
\hline SMA & 18 & $35,3 \%$ \\
\hline DIPLOMA & 5 & $9,8 \%$ \\
\hline SARJANA & 2 & $3,9 \%$ \\
\hline Total & 51 & 100,0 \\
\hline
\end{tabular}

Sumber: Data Primer

Berdasarkan tabel 4.3 dapat diketahui bahwa sebagian besar dari pendidikan responden yaitu lulusan SD sebanyak 12 orang $(23,5 \%)$, lulusan SMP sebnayak 14 orang $(27,5 \%)$, lulusan SMA sebanyak 18 orang (35, $3 \%)$, lulusan DIPLOMA sebanyak 5 orang $(9,8 \%)$, lulusan SARJANA sebanyak 2 orang $(3.9 \%)$.

Tabel 4.4

Distribusi Frekuensi Subjek Penelitian Menurut Pekerjaan di Wilayah Kerja Puskesmas Sudiang Raya Kota Makassar 2019

\begin{tabular}{lll}
\hline $\begin{array}{l}\text { Jenis } \\
\text { Pekerjaan }\end{array}$ & $\begin{array}{l}\text { Frekuensi } \\
(\mathrm{f})\end{array}$ & $\begin{array}{l}\text { Presentase } \\
(\%)\end{array}$ \\
\hline Wiraswasta & 12 & $23,5 \%$ \\
PNS & 6 & $11,8 \%$ \\
IRT & 25 & $49,0 \%$ \\
Tidak & 8 & $15,7 \%$ \\
Bekerja & & \\
\hline Total & 51 & 100,0 \\
\hline
\end{tabular}

Sumber : Data Primer

Berdasarkan tabel 4.4 dapat diketahui bahwa penderita Diabetes Melitus Tipe 2 di Wilayah Kerja Puskesmas Sudiang Raya Kota Makassar berdasarkan jenis pekerjaan yaitu Wiraswasta sebanyak 12 orang $(23,5 \%)$, PNS sebanyak 6 orang $(11,8 \%)$, IRT sebanyak 25 orang (49,0\%), Tidak Bekerja sebanyak 8 orang $(15,7 \%)$. Rata-rata pekerjaan yang di dapatkan adalah IRT dengan presentase $49,0 \%$. 
Tabel 4.7

Distribusi Frekuensi Responden Menurut

Pengetahuan di Wilayah Kerja Puskesmas Sudiang Raya Kota Makassar 2019

\begin{tabular}{lll}
\hline Pengetahuan & $\begin{array}{l}\text { Frekuensi } \\
\text { (f) }\end{array}$ & $\begin{array}{l}\text { Presentase } \\
(\%)\end{array}$ \\
\hline BAIK & 40 & $78,4 \%$ \\
CUKUP & 11 & $21,6 \%$ \\
\hline Total & 51 & 100,0 \\
\hline
\end{tabular}

Sumber : Data Primer

Berdasarkan tabel 4.7 dapat diketahui bahwa penderita penderita diabetes melitus tipe 2 di Wilayah Kerja Puskesmas Sudiang Raya Kota Makassar tingkat pengetahuan yang baik yaitu sebanyak 40 orang (78, $4 \%)$, dan yang memiliki penegetahuan cukup yaitu sebanyak 11 orang $(21,6 \%)$.

Tabel 4.8

Distribusi Frekuensi Responden Menurut Motivasi Di Wilayah Kerja Puskesmas Sudiang Raya Kota Makassar 2019

\begin{tabular}{lll}
\hline Motivasi & $\begin{array}{l}\text { Frekuensi } \\
\text { (f) }\end{array}$ & Presentase (\%) \\
\hline BAIK & 31 & $60,8 \%$ \\
KURANG & 20 & $39,2 \%$ \\
\hline Total & 51 & 100,0 \\
\hline
\end{tabular}

Sumber: Data Primer

Berdasarkan tabel 4.8 dapat diketahui bahwa penderita diabetes melitus tipe 2 di Wilayah Kerja Puskesmas Sudiang Raya Kota Makassar dapat diketahui kategori motivasi yang baik yaitu sebanyak 31 orang $(60,8 \%)$, dan motivasi kurang yaitu sebanyak 20 orang $(39,2 \%)$.

Tabel 4.9

Distribusi Frekuensi Responden Menurut Sikap di Wilayah Kerja Puskesmas Sudiang Raya Kota Makassar 2019

\begin{tabular}{lll}
\hline Sikap & $\begin{array}{l}\text { Frekuensi } \\
(\mathrm{f})\end{array}$ & $\begin{array}{l}\text { Presentase } \\
(\%)\end{array}$ \\
\hline BAIK & 28 & $54,9 \%$ \\
KURANG & 23 & $45,1 \%$ \\
\hline Total & $\mathbf{5 1}$ & $\mathbf{1 0 0 , 0}$ \\
\hline
\end{tabular}

Sumber : Data Primer

Berdasarkan tabel 4.9 dapat diketahui bahwa penderita diabetes melitus tipe 2 di Wilayah Kerja Puskesmas Sudiang Raya Kota Makassar yang memiliki sikap baik yaitu 28 orang $(54,9 \%)$,dan yang memiliki sikap kurang yaitu 23 orang $(45,1 \%)$.
Tabel 4.10

Distribusi Frekuensi Responden Menurut Kepatuhan Diet di Wilayah Kerja Puskesmas Sudiang Raya Kota Makassar 2019

\begin{tabular}{lll}
\hline Sikap & $\begin{array}{l}\text { Frekuensi } \\
\text { (f) }\end{array}$ & Presentase (\%) \\
\hline BAIK & 41 & $80,4 \%$ \\
KURANG & 10 & $19,6 \%$
\end{tabular}

\begin{tabular}{lll}
\hline Total & 51 & 100,0 \\
\hline
\end{tabular}

Sumber : Data Primer

Berdasarkan tabel 4.10 dapat diketahui bahwa penderita diabetes tipe 2 di Wilayah Kerja Puskesmas Sudiang Raya Kota Makassar untuk kepatuhan diet yaitu patuh sebanyak 41 orang $(80,4 \%)$, dan yang tidak patuh sebanyak 10 orang (19,6\%).

\section{Analisis Bivariate}

Analisis bivariate yaitu untuk menganalisis hubungan pengetahuan, motivasi dan sikap dengan kepatuhan diet pada penderita diabetes melitus tipe 2 di Wilayah Kerja Puskesmas Sudiang Raya Kota Makassar dengan menggunakan uji Chi Square.

\section{Tabel 4.11}

Hubungan Pengetahuan dengan Kepatuhan Diet pada Penderita Diabetes Melitus Tipe 2 di Wilayah Kerja Puskesmas Sudiang Raya Kota Makassar 2019

\begin{tabular}{|c|c|c|c|c|c|c|c|}
\hline \multirow{3}{*}{$\begin{array}{l}\text { Peng } \\
\text { etah } \\
\text { uan }\end{array}$} & \multicolumn{4}{|c|}{ Kepatuhan diet } & \multicolumn{2}{|c|}{ Total } & \multirow{4}{*}{$\begin{array}{l}p \\
0,0 \\
00\end{array}$} \\
\hline & \multicolumn{2}{|c|}{ Patuh } & \multicolumn{2}{|c|}{$\begin{array}{l}\text { Tidak } \\
\text { patuh }\end{array}$} & \multirow[t]{2}{*}{$\mathrm{n}$} & \multirow[t]{2}{*}{$\%$} & \\
\hline & $f$ & $\%$ & $F$ & $\%$ & & & \\
\hline Baik & $\begin{array}{l}3 \\
7\end{array}$ & $\begin{array}{l}90, \\
2\end{array}$ & 3 & 30,0 & $\begin{array}{l}4 \\
0\end{array}$ & 78,4 & \\
\hline $\begin{array}{l}\text { Cuk } \\
\text { up }\end{array}$ & 4 & 9,8 & 7 & 70,0 & $\begin{array}{l}1 \\
1\end{array}$ & 21,6 & \\
\hline Total & $\begin{array}{l}4 \\
1\end{array}$ & $\begin{array}{l}10 \\
0,0\end{array}$ & $\begin{array}{l}1 \\
0\end{array}$ & $\begin{array}{l}100, \\
0\end{array}$ & $\begin{array}{l}5 \\
1\end{array}$ & $\begin{array}{l}100 \\
, 0\end{array}$ & \\
\hline
\end{tabular}

Sumber: Data Primer

Berdasarkan tabel 4.11 diperoleh data bahwa dari 51 responden lebih banyak yang memiliki pengetahuan baik dengan tingkat kepatuhan diet yaitu patuh 37 orang $(90,2 \%)$ dan tidak patuh sebanyak 3 orang $(30,0 \%)$, sedangkan responden yang memiliki pengetahuan cukup lebih sedikit dengan tingkat kepatuhan diet yang patuh sebanyak 4 orang $(9,8 \%)$ dan tidak patuh sebanyak 7 orang $(70,0 \%)$.

Hasil uji statistik (uji chi square) diketahui bahwa terdapat hubungan yang bermakna antara pengetahuan dengan kepatuhan diet pada penderita diabetes melitus tipe 2 di Wilayah Kerja Puskesmas Sudiang Raya Kota Makassar $(p \leq 0,05)$. 
Tabel 4.12

Hubungan Motivasi dengan Kepatuhan Diet pada Penderita Diabetes Melitus Tipe 2 di Wilayah Kerja Puskesmas Sudiang Raya Kota Makassar 2019

\begin{tabular}{|c|c|c|c|c|c|c|c|}
\hline \multirow{3}{*}{$\begin{array}{l}\text { Moti } \\
\text { vasi }\end{array}$} & \multicolumn{4}{|c|}{ Kepatuhan diet } & \multicolumn{2}{|c|}{ Total } & \multirow{3}{*}{$\begin{array}{l}p \\
0,00\end{array}$} \\
\hline & \multicolumn{2}{|c|}{ Patuh } & \multicolumn{2}{|c|}{$\begin{array}{l}\text { Tidak } \\
\text { patuh }\end{array}$} & \multirow[t]{2}{*}{$\mathrm{n}$} & \multirow[t]{2}{*}{$\%$} & \\
\hline & $f$ & $\%$ & $f$ & $\%$ & & & \\
\hline Baik & 21 & 51,2 & 10 & $\begin{array}{l}100, \\
0\end{array}$ & 31 & 60,8 & 3 \\
\hline $\begin{array}{l}\text { Kura } \\
\text { ng }\end{array}$ & 20 & 48,8 & 0 & 0,0 & 20 & 39,2 & \\
\hline $\begin{array}{l}\text { Tota } \\
1\end{array}$ & 41 & $\begin{array}{l}100, \\
0\end{array}$ & 10 & $\begin{array}{l}100, \\
0\end{array}$ & 51 & $\begin{array}{l}100 \\
, 0\end{array}$ & \\
\hline
\end{tabular}

Sumber: Data Primer

Berdasarkan tabel 4.12 diperoleh data bahwa dari 51 responden lebih banyak yang memiliki motivasi baik dengan tingkat kepatuhan diet yaitu patuh 21 orang $(51,2 \%)$ dan tidak patuh sebanyak 10 orang $(100,0 \%)$, dibandingkan responden yang memiliki pengetahuan kurang lebih sedikit dengan tingkat kepatuhan diet yang patuh sebanyak 20 orang $(48,8 \%)$ dan tidak patuh sebanyak 0 orang $(0,0 \%)$.

Hasil uji statistik (uji chi square) diketahui bahwa terdapat hubungan yang bermakna antara motivasi dengan kepatuhan diet pada penderita diabetes melitus tipe 2 di Wilayah Kerja Puskesmas Sudiang Raya Kota Makassar $(p \leq 0,05)$.

Tabel 4.13

Hubungan Sikap dengan Kepatuhan Diet pada

Penderita Diabetes Melitus Tipe 2 di Wilayah Kerja Puskesmas Sudiang Raya Kota Makassar 2019

\begin{tabular}{|c|c|c|c|c|c|c|c|}
\hline \multirow[t]{3}{*}{ Sikap } & \multicolumn{4}{|c|}{ Kepatuhan diet } & \multicolumn{2}{|c|}{ Total } & \multirow{3}{*}{$\begin{array}{l}p \\
0,00\end{array}$} \\
\hline & \multicolumn{2}{|c|}{ Patuh } & \multicolumn{2}{|c|}{$\begin{array}{l}\text { Tidak } \\
\text { patuh }\end{array}$} & \multirow[t]{2}{*}{$\mathrm{n}$} & \multirow[t]{2}{*}{$\%$} & \\
\hline & $f$ & $\%$ & $f$ & $\%$ & & & \\
\hline Baik & 18 & 43,9 & 10 & $\begin{array}{l}100, \\
0\end{array}$ & 28 & 54,9 & 1 \\
\hline $\begin{array}{l}\text { Kuran } \\
\mathrm{g}\end{array}$ & 23 & 56,1 & 0 & 0,0 & 23 & 45,1 & \\
\hline Total & 41 & $\begin{array}{l}100, \\
0\end{array}$ & 10 & $\begin{array}{l}100, \\
0\end{array}$ & 51 & $\begin{array}{l}100 \\
, 0\end{array}$ & \\
\hline
\end{tabular}

Sumber: Data Primer

Berdasarkan tabel 4.11 diperoleh data bahwa dari 51 responden yang memiliki sikap baik dengan tingkat kepatuhan diet lebih sedikit yaitu patuh 18 orang $(43,9 \%)$ dan tidak patuh sebanyak 10 orang $(100,0 \%)$, dibanding dengan responden yang memiliki sikap kurang dengan tingkat kepatuhan diet lebih banyak yang patuh sebanyak 23 orang $(56,1 \%)$ dan tidak patuh sebanyak 0 orang $(0,0 \%)$.

Hasil uji statistik (uji chi square) diketahui bahwa terdapat hubungan yang bermakna antara sikap dengan kepatuhan diet pada penderita diabetes melitus tipe 2 di Wilayah Kerja Puskesmas Sudiang Raya Kota Makassar $(p \leq 0,05)$.

\section{PEMBAHASAN HASIL PENELITIAN}

1. Hubungan Pengetahuan dengan Kepatuhan Diet

Dari hasil penelitian yang diperoleh berdasarkan uji statistik (chi square) diperoleh nilai $(p=0,000 \leq a=0,05)$ yang berarti terdapat hubungan yang bermakna antara pengetahuan dengan kepatuhan diet pada penderita diabetes melitus tipe 2 di Wilayah Kerja Puskesmas Sudiang Raya Kota Makassar.

Hasil penelitian ini sejalan dengan penelitian yang dilakukan Phitri dan Widyaningsih (2013), yang menyimpulkan bahwa ada hubungan pengetahuan dengan kepatuhan diet diabetes melitus.

Menurut Notoadmojo, (2003) dalam Lestari, (2015) mengatakan pengetahuan merupakan hasil tahu, dan ini terjadi setelah orang melakukan pengindraan terhadap obyek tertentu. Pengindraan panca indra manusia yaitu indra penglihatan, pendengaran, penciuman, rasa dan raba. Sebagian besar pengetahuan manusia diperoleh melalui mata dan telinga, yaitu proses melihat dan mendengar. Selain itu proses pengalaman dan proses belajar dalam pendidikan formal maupun informal.

Menurut asumsi peneliti berdasarkan hasil penelitian yang didapatkan bahwa adanya hubungan yang bermakna antara pengetahuan dengan kepatuhan diet karena pengetahuan merupakan faktor yang berpengaruh terhadap kepatuhan diet maka dari itu pengetahuan juga penting untuk memberntuk atau merubah tindakan seseorang dan rata-rata penderita DM yang berada di Wilayah Kerja Puskesma Sudiang Raya memiliki tingkat pengetahuan yang baik, Responden yang memiliki pengetahuan yang baik lebih cendrung patuh, hal ini terjadi karena pengetahuan yang dimiliki responden mengenai diet DM akan menimbulkan kesadaran bagi responden dan akhirnya akan menyebabkan berperilaku sesuai dengan apa yang mereka ketahui. Pengetahuan responden didapat dari pengalaman, penyuluhan kesehatan, informasi dari petugas kesehatan.Oleh karena itu, pada penelitian ini responden dengan pengetahuan 
baik patuh dalam menjalankan segala anjuran diet dari dokter/tenaga kesehatan karena mereka mengetahui bahwa apabila mereka tidak patuh dalam menjalankan diet maka akibatnya mereka akan lebih mudah terkena komplikasi DM.

2. Hubungan Motivasi dengan Kepatuhan Diet

Dari hasil penelitian yang diperoleh berdasarkan uji statistik (chi square) diperoleh nilai $(p=0,003 \leq \alpha=0,05)$ yang berarti terdapat hubungan yang bermakna antara motivasi dengan kepatuhan diet pada penderita diabetes melitus tipe 2 di Wilayah Kerja Puskesmas Sudiang Raya Kota Makassar.

Hasil penelitian ini sejalan dengan penelitian yang dilakukan oleh Indarwati, D. et all (2012) yang menyimpulkan bahwa ada hubungan antara motivasi dengan kepatuhan diet diabetes melitus.

Motivasi merupakan salah satu faktor yang memberikan pengaruh terhadap kepatuhan penderita. Oleh karena itu penderita membutuhkan motivasi dari keluarga atau orang terdekat dalam menjalankan kepatuhan diet penderita DM tipe 2

Hasil penelitian ini juga sejalan dengan penelitian yang dilakukan oleh Azis dan Aminah (2018), yang menyimpulkan bahwa ada hubungan antara motivasi dengan kepatuhan diet diabetes melitus tipe 2

Menurut asumsi peneliti berdasarkan hasil penelitian yang didapatkan bahwa adanya hubungan yang bermakna antara motivasi dengan kepatuhan diet ini dikarenakan motivasi adalah sebuah proses untuk mencapai suatu tujuan (Donsu, 2017).. Rata-rata penderita DM yang berada di Wilayah Kerja Puskesma Sudiang Raya memiliki motivasi yang baik, Motivasi yang baik dari responden kemungkinan disebabkan oleh adanya keinginan yang kuat dari dalam diri responden untuk sembuh dan terhindar dari berbagai komplikasi yang diakibatkan oleh DM. Mereka mengetahui konsekwensi akibat ketidakpatuhan tersebut dapat membuat gula darah meraka tidak stabil, sehingga menyulitkan penyembuhan dan meningkatkan resiko komplikasi sehingga adanya keinginan untuk terhindar dari hal-hal negatif tersebut

3. Hubungan Sikap dengan Kepatuhan Diet

Dari hasil penelitian yang diperoleh berdasarkan uji statistik (chi square) diperoleh nilai $(p=0,001 \leq a=0,05)$ yang berarti terdapat hubungan yang bermakna antara Sikap dengan kepatuhan diet pada penderita diabetes melitus tipe 2 di Wilayah Kerja Puskesmas Sudiang Raya Kota Makassar.

Hasil penelitian ini sejalan dengan penelitian yang dilakukan Phitri dan Widyaningsih (2013), yang melakukan penelitian tentang sikap penderita Diabetes Melitus dengan kepatuhan diet menyimpulkan bahwa ada hubungan yang bermakna antara sikap dengan kepatuhan diet diabetes melitus.

Sikap merupakan kecenderungan seseorang melakukan tindakan setelah mendapatkan stimulus yang muncul dari dalam dirinya (Donsu, 2017).

Menurut asumsi peneliti berdasarkan hasil penelitian yang didapatkan bahwa adanya hubungan yang bermakna antara sikap dengan kepatuhan diet ini dikarenakan sikap merupakan satu faktor yang mempengaruhi kepatuhan dalam menjalankan diet. Salah satu faktor yang mendukung seperti pengaruh dari orang lain juga sangat berpengaruh untuk merubah sikap seseorang dalam mewujudkan perilaku yang positif. Rata-rata penderita DM yang berada di Wilayah Kerja Puskesma Sudiang Raya menunjukkan responden yang memiliki sikap yang kurang cenderung mematuhi diet sedangkan responden yang mempunyai sikap baik sebagian besar tidak mematuhi diet yang dianjurkan oleh dokter. Banyaknya responden yang memiliki sikap kurang baik dan patuh dalam menjalankan diet kemungkinan dikarenakan mereka terdorong untuk patuh, karena mereka mengetahui konsekwensi akibat ketidakpatuhan tersebut dapat membuat gula darah meraka tidak stabil, Responden yang mendukung bahwa diet DM harus dilakukan untuk mencegah komplikasi diabetes melitus maka responden akan mematuhi diet diabetes dengan cara memiliki informasi yang cukup akan memperbaiki keterampilan dan sikap penyandang DM.

\section{KESIMPULAN}

Berdasarkan hasil penelitian yang telah dijelaskan maka dapat disimpulkan sebagai berikut:

1. Ada hubungan yang bermakna antara pengetahuan dengan kepatuhan diet pada penderita diabetes melitus tipe 2 di Wilayah Kerja Puskesmas Sudiang Raya Kota Makassar yaitu $(p \leq 0,05)$

2. Ada hubungan yang bermakna antara motivasi dengan kepatuhan diet pada penderita diabetes melitus tipe 2 di Wilayah 


\begin{tabular}{ll}
\hline \hline Kerja Puskesmas Sudiang Raya Kota & yang menderita DM dalam meningkatkan \\
Makassar yaitu $(p \leq 0,03)$ & $\begin{array}{l}\text { kepatuhan dietnya agar dapat mencegah } \\
\text { terjadinya komplikasi lebih lanjut. }\end{array}$ \\
3. Ada hubungan yang bermakna antara sikap & Bagi masyarakat \\
dengan kepatuhan diet pada penderita & Kepada mayarakat atau pasien di sarankan \\
diabetes melitus tipe 2 di Wilayah Kerja & jika ingin mendapatkan kadar gula darah \\
Puskesmas Sudiang Raya Kota Makassar & yang baik maka dianjurkan untuk \\
yaitu $(p \leq 0,01)$. & menjalankan perilaku hidup sehat dan perlu \\
kARAN & keaktifan dalam mencari informasi \\
Berdasarkan kesimpulan dari penemuan- & mengenai diabetes melitus yang bisa \\
penemuan masalah dan hasil penelitian ini, & diperoleh melalui media massa misalnya \\
peneliti memberikan saran sebagai berikut: & TV, radio, Koran, penyuluhan di peskesmas \\
1. Bagi peneliti lain & dan lain-lain. Dan dapat pula berdiskusi \\
Diharapkan bagi peneliti selanjutnya untuk & dengan perawat atau dokter. \\
meneliti beberapa variabel lainnya yang & Bagi puskesmas \\
belum diteliti dan menggunakan metode & Disarankan perlu adanya pengembangan \\
penelitian yang berbeda. & pemberian informasi tentang Diabetes \\
Bagikeluarga & Melitus seperti pemasangan spanduk, dll di \\
Disarankan anggota keluarga dapat & Puskesmas maupun sekitar Wilayah Kerja \\
meningkatkan motivasi anggota keluarga & Puskesmas
\end{tabular}

\section{DAFTAR PUSTAKA}

Anggraeni,D.M \& Saryono. (2017). Metodologi Penelitian Kualitatif dan Kuantitatif Dalam Bidang Kesehatan. Yogyakarta: Nuha Medika

Azis, et all (2018). Pengetahuan, Motivasi dan Kepatuhan Diet Pasien DM Tipe II di Wilayah Kerja Puskesmas Kaliwungu Kendal. (1), 72-79.http://stikesyahoedsmg.ac.id/ojs/index.php/sjkp/article/download/159/pdf

Badan Penelitian Dan pengembangan kesehatan Kementrian Kesehatan RI Tahun 2015 http://www.depkes.go.id/ (Diakses Pada Tanggal 14 Februari 2019)

Damayanti, Santi. (2015). Diabetes Melitus \& Penatalaksanaan Keperawatan. Yogyakarta: Nuha Medika

Donsu, Jenita Doli Tine. (2017). PSIKOLOGI KEPERAWATAN Aspek-Aspek Psikologi Konsep Dasar Psikologi Teori Prilaku Manusia. Yogyakarta: PUSTAKA BARU PRESS

Donsu, Jenita Doli Tine. (2017). Metodologi PENELITIAN KEPERAWATAN. Yogyakarta: PUSTAKA BARU PRESS.

Dewi, T. et all (2018). Kepatuhan Diet Pasien Dm Berdasarkan Tingkat pengetahuan dan dukungan keluarga, 25, 55-63.

Essy Phitri, et all (2013). Hubungan Antara Pengetahuan Dan Sikap Penderita Diabetes Mellitus Dengan Kepatuhan Diet Diabetes Mellitus Di Rsud Am. Parikesit Kalimantan Timur. (1), 58-74.

Harmiatin. (2017). Dukungan keluarga terhadap kepatuhan diet diabetes melitus pada penderita diabetes melitus di poli penyakit dalam di rumah sakit umum bahterahmas.

H.R Hasdianah. (2018). Mengenal DIABETES MELLITUS PADA ORANG DEWASA DAN ANAK-ANAK DENGAN SOLUSI HERBAL. Yogyakarta: Nuha Medika.

Handayani D \& Rudijanto A. (2015). Penatalaksanaan Gizi Pada Diabetes Melitus. Malang: UBMedika 
Jurnal Media Keperawatan: Politeknik Kesehatan Makassar

Vol. 10 No. 022019

e-issn :2622-0148, p-issn : 2087-0035

Hidayat, A. Aziz Alimul. (2017). Metodologi Penelitian Keperawatan dan Kesehatan. Jakarta: Salemba Medika.

Internasional diabetes federation 2017 online version atlas eight edition 2017 : http://diabetesasia.org/ (diakses pada tanggal 15 februari 2019)

Indarwati, D. et all (2012). Hubungan Motivasi Dengan Kepatuhan Diet Diabetes Melitus Pada Pasien Diabetes Melitus Di Desa Tangkil Wilayah Kerja Puskesmas Kedungwuni II Kabupaten Pekalongan. https:/le-skripsi.stikesmuhpkj.ac.id/detail/absdownload/301

Khotimah, K . (2014). Sehat dan Lezat Menu Untuk Penderita Diabetes Melitus. Yogyakarta: Rapha.

Lestari, titik. (2015).Kumpulan Teori Untuk Kajian pustaka Penelitian Kesehatan. Yogyakarta: Nuhamedika.

Nuari, NA. (2017). Strategi Manajemen Edukasi Pasien Diabetes Melitus. Yogyakarta: Cv Budi Utama.

Nursalam. (2017). Metodologi Penelitian IImu Keperawatan Pendekatan Praktis Edisi 4. Jakarta Selatan: Salemba Medika.

PERKENI 2015 . Konsensus Pengelolaan dan Pencegahan Diabetes mellitus tipe 2 https://pbperkeni.or.id/ (diakses pada tanggal 14 februari 2019)

P. Restuning, D. (2015). Efektifitas Edukasi Diabetes dalam Meningkatkan Kepatuhan Pengaturan Diet pada Diabetes Melitus Tipe 2. Mutiara Medika, 15(1), 37-41.

Pujiastuti, E. (2017). Hubungan Pengetahuan Dan Motivasi Dengan Kepatuhan Diet Pada Pasien Diabetes Mellitus Tipe li Di Poliklinik Penyakit Dalam Rsud Dr. Soehadi Prijonegoro Sragen, 0-11.

Riskesdas. (2018) Riset Kesehatan Dasar. http://www.kemkes.go.id/ (Diakses pada Tanggal 14 Februari 2019).

Rumahorbo, Hotma. (2014). Mencegah Diabetes Melitus Dengan Perubahan Gaya Hidup. Bogor: In Medika

Riyanto, Agus. (2017). Aplikasi Metodologi Penelitian Kesehatan. Yogyakarta: Nuha Medika.

Syamsiah, Nur. (2017). Berdamai Dengan DIABETES. Jakarta: Tim Bumi Medika.

Sukardji \& Basuki. (2018). PENATALAKSANAAN DIABETES MELITUS TERPADU Edisi Kedua. Jakarta: FKUI

Tandra, Hans. (2017). Segala Sesuatu Yang harus Anda Ketahui Tentang DIABETES. Jakarta: PT Gramedia Pustaka Utama.

Tholib, Ali, Maghfuri. (2016). Buku Pintar Perawatan Luka Diabetes Melitus. Jakarta Selatan: Salemba Medika.

Word Health Organization.2016.Global Report On Diabetes.http://apps.who.int. (Diakses pada Tanggal 14 Februari 2019)

Wawan. A \& M. Dewi. (2011). Teori \& Pengukuran PENGETAHUAN, SIKAP, DAN PERILAKU MANUSIA. Yogyakarta: Nuha Medika 